\title{
UPAYA PENINGKATAN MOTORIK HALUS ANAK DENGAN RETARDASI MENTAL MELALUI TERAPI BERMAIN : PARALLEL PLAY MENGANYAM KERTAS
}

\author{
Siska Christianingsih* \\ *STIKes William Booth Surabaya, Jl.Cimanuk No.20 Surabaya \\ Email: siskaaksis89@yahoo.com
}

\begin{abstract}
ABSTRAK
Anak retardasi mental umumnya memiliki kemampuan motorik kasar dan halus yang lebih rendah dibandingkan anak normal, karena kelemahan pada sistem saraf sehingga sulit mencapai perkembangan secara normal. Hal tersebut dapat ditingkatkan dengan memberikan stimulasi yang baik dan berkesinambungan. Terapi bermain: Parallel Play menganyam kertas merupakan permainan aktif mandiri anak retardasi mental untuk meningkatkan kemampuan motorik halus. Penelitian ini menggunakan desain Quasy Experimental. Populasinya adalah anak usia 11-12 tahun di SDLB AKW Kumara II. Sampel terdiri dari 12 responden dengan purposive sampling sesuai kriteria inklusi. Pengumpulan data dilakukan dengan lembar observasi dan dianalisis dengan Wilcoxon Signed Rank Test dan Mann Whitney U Test dengan tingkat signifikan $\alpha \leq 0,05$. Hasil penelitian menunjukkan bahwa Terapi bermain: Parallel Play menganyam kertas dapat meningkatkan motorik halus anak retardasi mental. Hasil uji Wilcoxon pada kelompok perlakuan didapatkan data nilai $\mathrm{p}=0.026$ dan kelompok kontrol $\mathrm{p}=$ 0.063. Uji statistik menggunakan Mann Whitney U Test menunjukkan motorik halus pada kelompok perlakuan lebih baik daripada kelompok kontrol (nilai $\mathrm{p}=0,030$ ). Kesimpulannya, terapi bermain: parallel play menganyam kertas dapat meningkatkan motorik halus anak retardasi mental ringan.
\end{abstract}

Kata kunci : anak retardasi mental, perkembangan motorik halus, terapi bermain, menganyam kertas

\section{ABSTRACT}

Child with mental retardation generally has lower gross and fine motor skills than normal child, because of their weakness in the nervous system making it difficult to achieve motion in the sequence of normal development. It can be increased by giving good and continuous stimulations. Parallel Playing Therapy: Plaiting Paper is an independently active game of mentally retarded children to increase their fine motor skill. This study used Quasy Experimental design. The population was children 11-12 years old at AKW Kumara II inclusive school. The sample consist of 12 respondents with purposive sampling according to the inclusion criteria. Data were collected by observation sheet and analysed by Wilcoxon Signed Rank Test and Mann Whitney U Test with level of significance $\alpha \leq 0.05$. The result showed that Parallel Playing Therapy: Plaiting Paper can improve mentally retarded children's fine motor. The result of Wilcoxon test in the intervention group was $p=0.026$ and in the control group was $p=0.063$. Statistic test using Mann Whitney U Test showed fine motor in the intervention group better than control group (value $p=0.030$ ). In conclusion, parallel playing therapy: plaiting paper can increase fine motor of mentally retarded children.

Keyword: mentally retarded child, fine motor development, parallel plating therapy, plaiting paper 


\section{Pendahuluan}

Retardasi mental adalah salah satu disabilitas yang paling umum terjadi di masa anak-anak (Raina, Razdan \& Nanda, 2012). Anak retardasi mental (tuna grahita) umumnya memiliki kecakapan motorik yang lebih rendah dibanding kelompok anak normal sebaya, baik secara kualitatif maupun kuantitatif. Hal ini ditunjukkan dengan kurang mampunya anak dalam melakukan aktivitas motorik yang membutuhkan gerakan serta koordinasi motorik yang lebih kompleks (Sunardi \& Sunaryo, 2007). Anak normal dapat mempelajari kecapakan gerakan motorik secara naluri atau insting pada saat bermain, berbeda dengan anak retardasi mental memerlukan pelatihan secara khusus (Somantri, 2006). Anak dengan gangguan perkembangan mempunyai kelemahan pada keterampilan motorik kasar maupun halus, sistem imunitas, serta koordinasi gerak tubuh (Delphie, 2006).

Sekitar 1-4 \% populasi dunia mengalami retardasi mental dengan berbagai tingkat keparahan. Besaran angka retardasi mental tertinggi berada di negara berkembang dikarenakan permasalahan lingkungan, gizi, penyakit dan kemiskinan (Islam, Farjana \& Shanhnaz, 2013). Dengan pendekatan modern dengan menggunakan nilai intelegensi dan perilaku yang adaptif sebagai parameter pada populasi umum maka prevalensi retardasi mental adalah sekitar $1 \%$, retardasi mental ringan $0,37 \%-0,59 \%$ dan retardasi mental sedang sampai berat adalah 0,3\% - 0,4\% . Prevalensi di Amerika Serikat, gangguan kombinasi retardasi mental adalah 1,58\% sedangkan retardasi mental saja sebesar 0,78\%. (Elvira, 2010). Di Indonesia 1-3\% penduduknya menderita retardasi mental. Angka kejadian retardasi mental tertinggi terjadi pada anak usia 10-14 tahun dan terjadi pada laki-laki 1,5 kali lebih besar dibanding perempuan.

Penyebab retardasi mental terutama adalah genetik, biokimia, dan infeksi. Keterlambatan secara khas pada anak retardasi mental terlihat pada perkembangan motoric halus dan kasar serta bicara, walaupun keterlambatan yang paling banyak di prediksi (Wong, 2009). Sifat dasar genetic, termasuk bentuk tubuh dan kecerdasan mempunyai pengaruh yang menonjol terhadap laju perkembangan motoric (Hurlock, 2010). Anak dengan retardasi mental akan mengalami keterbatasan kemampuan motorik apabila tidak segera diberikan latihan khusus (Mahmudah, 2002). Perkembangan motorik yang terlambat berpengaruh pada penyesuaian sosial dan pribadi anak. Anak dengan retardasi mental memerlukan kemampuan motorik halus yang terkoordinasi baik agar dapat menjalankan aktivitas dengan baik. Keterampilan 
motorik dapat berkembang dengan baik melalui pembelajaran (Hurlock, 2010).

Pengalaman dan pembelajaran merupakan faktor yang menentukan dalam perkembangan kepribadian anak. John Locke (1632-1704) menciptakan teori "tabula rasa" yang menyatakan pentingnya pengaruh pengalaman dan lingkungan sekitar pada perkembangan anak. Stimulasi menjadi sesuatu yang penting dan dibutuhkan anak, namun dalam memberikan stimulasi perlu memperhatikan waktu yang tepat, yaitu pada saat anak siap dan sensitive untuk memperoleh stimulasi (Gunarsa, 2008). Keterampilan motorik dapat dirangsang melalui permainan yang membuat anak bergerak menggunakan tumpuan otot, keseimbangan, kelenturan serta gerakangerakan motorik halus seperti, melukis, menjahit, menganyam atau menulis ( Musfiroh, 2008). Terapi bermain: parallel play adalah permainan bersifat aktif secara mandiri, namun dalam satu kelompok, dengan harapan kemampuan anak dalam menyelesaikan tugas mandiri dalam kelompk tersebut terlatih dengan baik (Hidayat, 2008). Salah satu model parallel play adalah menganyam kertas. Kemampuan kognitif pada anak usia sekolah dasar dapat menjadi panduan untuk memberikan stimulasi kecakapan yang dapat mengembangkan pola pikir atau daya nalar (Yusuf, 2005). Anak dengan retardasi mental yang telah mendapatkan stimulus motorik halus diharapkan mampu meningkatkan kualitas aktifitas dalam kehiduan sehari-hari. Sehingga peneliti tertarik untuk meneliti upaya peningkatan motorik halus anak dengan retardasi mental melalui terapi bermain: parallel play menganyam kertas.

\section{METODE DAN ANALISA}

Desain pada penelitian ini adalah quasy experiment (two group pre-post test design). Populasi pada penelitian ini adalah siswa SDLB Kumara II Surabaya yang berjumlah 38 siswa. Pengambilan sampel menggunakan teknik purposive sampling. Sampel penelitian ini adalah siswa retardasi mental ringan usia 11-12 tahun dan berdasarkan kriteria inklusi dan eksklusi yang telah ditentukan oleh peneliti selama pengambilan data berlangsung. Kriteria Inklusinya sebagai berikut: 1) Penyandang retardasi mental ringan (IQ 50-70), 2) Siswa yang belum pernah mendapatkan kegiatan mengayam kertas, 3) Siswa yang aktif hadir dalam mengikuti pelatihan, 4) Mendapat persetujuan dari orang tua. Jumlah sampel penelitian ini sebesar 12 siswa. Kelompok perlakuan diberikan intervensi pelatihan menganyam kertas sedangkan kelompok kontrol hanya diberikan kegiatan sesuai dengan jadwal sekolah. Kelompok perlakuan diberikan permainan menganyam kertas dalam 3 kali 
perminggu, selama 40 menit setiap pertemuan dalam 3 minggu. Masingmasing kelompok dilakukan pre test dan post test. Analisis data menggunakan Uji Wilcoxon Signed Rank Test dan Uji MannWhitney. Instrument untuk mengukur perkembangan motorik halus pada penelitian ini dikembangkan dari alat ukur Delphie (2006) yang telah dilakukan uji validitas dan reliabilitas oleh peneliti.

\section{HASIL DAN PEMBAHASAN}

\section{Data Karakteristik Responden}

Tabel 1.1 Distribusi Frekuensi Karakteristik Responden Berdasarkan Usia

\begin{tabular}{ccc}
\hline $\begin{array}{c}\text { Karakteristik } \\
\text { Responden } \\
\text { Berdasarkan } \\
\text { Usia }\end{array}$ & $\begin{array}{c}\text { Frekuensi } \\
(\mathbf{n})\end{array}$ & $\begin{array}{c}\text { Presentase } \\
(\boldsymbol{\%})\end{array}$ \\
\hline 11 tahun & & \\
12 tahun & 3 & $25 \%$ \\
\hline Total & 9 & $75 \%$ \\
\hline
\end{tabular}

Tabel 1.1 menunjukkan bahwa sebagian besar responden berada pada usia 2 tahun.

Tabel 1.2 Distribusi Frekuensi Karakteristik Responden Berdasarkan Jenis Kelamin.

\begin{tabular}{lcc}
\hline $\begin{array}{l}\text { Karakteristik } \\
\text { Responden } \\
\text { Berdasarkan }\end{array}$ & $\begin{array}{c}\text { Frekuensi } \\
(\mathbf{n})\end{array}$ & $\begin{array}{c}\text { Presentase } \\
(\boldsymbol{\%})\end{array}$ \\
Jenis Kelamin & & \\
\hline \multicolumn{1}{c}{ Laki-laki } & 5 & $41,7 \%$ \\
Perempuan & 7 & $58,3 \%$ \\
\hline \multicolumn{1}{c}{ Total } & 12 & $100 \%$ \\
\hline
\end{tabular}

Tabel 1.2 menunjukkan bahwa sebagian besar responden adalah perempuan $(58,3 \%)$.
Tabel 1.3 Distribusi Frekuensi Karakteristik Orang Tua Berdasarkan Pendidikan

\begin{tabular}{|c|c|c|}
\hline $\begin{array}{ll}\text { Karakteristik } & \\
\text { Orang } & \text { Tua } \\
\text { Berdasarkan } & \\
\text { Pendidikan } & \end{array}$ & $\begin{array}{l}\text { Frekuensi } \\
\quad \text { (n) }\end{array}$ & $\begin{array}{l}\text { Presentase } \\
(\%)\end{array}$ \\
\hline Ayah & & \\
\hline SMP/sederajat & 1 & $8,3 \%$ \\
\hline SMA/sederajat & 7 & $58,4 \%$ \\
\hline $\begin{array}{l}\text { Perguruan Tinggi } \\
\text { Ibu }\end{array}$ & 4 & $33,3 \%$ \\
\hline SMP/sederajat & 2 & $16,7 \%$ \\
\hline SMA/sederajat & 9 & $75 \%$ \\
\hline Perguruan Tinggi & 1 & $8,3 \%$ \\
\hline Total & 12 & $100 \%$ \\
\hline
\end{tabular}

Tabel 1.3 menunjukkan bahwa sebagian Pendidikan ayah dan ibu responden adalah SMA/sederajat.

Tabel 1.3 Distribusi Frekuensi Karakteristik Orang Tua Berdasarkan Pendidikan

\begin{tabular}{lcc}
\hline $\begin{array}{l}\text { Karakteristik } \\
\text { Orang Tua } \\
\text { Berdasarkan }\end{array}$ & $\begin{array}{c}\text { Frekuensi } \\
\text { (n) }\end{array}$ & $\begin{array}{c}\text { Presentase } \\
(\%)\end{array}$ \\
Pendidikan & & \\
\hline$\quad$ Ayah & & \\
$\quad$ SMP/sederajat & 1 & $8,3 \%$ \\
$\quad$ SMA/sederajat & 7 & $58,4 \%$ \\
Perguruan Tinggi & 4 & $33,3 \%$ \\
& & \\
Ibu & & $16,7 \%$ \\
$\quad$ SMP/sederajat & 2 & $75 \%$ \\
$\quad$ SMA/sederajat & 9 & $8,3 \%$ \\
Perguruan Tinggi & 1 & $100 \%$ \\
\hline Total & & \\
\hline
\end{tabular}

Tabel 1.3 menunjukkan bahwa sebagian Pendidikan ayah dan ibu responden adalah SMA/sederajat. 
Tabel 1.3 Distribusi Frekuensi Karakteristik Orang Tua Berdasarkan Pekerjaan

\begin{tabular}{lcc}
\hline $\begin{array}{l}\text { Karakteristik Orang } \\
\text { Tua Berdasarkan } \\
\text { Pekerjaan }\end{array}$ & $\begin{array}{c}\text { Frekuensi } \\
(\mathbf{n})\end{array}$ & $\begin{array}{c}\text { Presentase } \\
(\%)\end{array}$ \\
\hline$\quad$ Ayah & & \\
PNS & 1 & $8,3 \%$ \\
Pegawai Swasta & 7 & $58,4 \%$ \\
Pedagang & 4 & $33,3 \%$ \\
$\quad$ Ibu & & \\
Pegawai Swasta & 3 & $25 \%$ \\
Pedagang & 5 & $41,7 \%$ \\
IRT & 4 & $33,3 \%$ \\
& & \\
\hline$\quad$ Total & 12 & $100 \%$ \\
\hline
\end{tabular}

Tabel 1.3 menunjukkan bahwa sebagian Pekerjan ayah dan ibu responden adalah pagawai swasta.

Identifikasi pengaruh terapi bermain: Parallel play Menganyam Kertas

Tabel 1.4 Data hasil Uji statistik upaya peningkatan motorik halus anak dengan retardasi mental melalui terapi bermain: parallel play menganyam kertas.

\begin{tabular}{|c|c|c|c|c|c|c|}
\hline \multirow{3}{*}{$\begin{array}{l}\text { No. } \\
\text { Res. }\end{array}$} & \multicolumn{6}{|c|}{ Skor perkembangan motorik halus } \\
\hline & \multicolumn{2}{|c|}{$\begin{array}{l}\text { Kelompok } \\
\text { perlakuan }\end{array}$} & \multirow{2}{*}{ Kategori } & \multicolumn{2}{|c|}{ Kelompok control } & \multirow{2}{*}{ Kategori } \\
\hline & Sebelum & Sesudah & & Sebelum & Sesudah & \\
\hline 1 & 20 & 25 & Baik & 12 & 14 & Cukup \\
\hline 2 & 22 & 30 & Baik & 16 & 18 & Cukup \\
\hline 3 & 12 & 18 & Cukup & 20 & 20 & Cukup \\
\hline 4 & 22 & 30 & Baik & 22 & 23 & Cukup \\
\hline 5 & 6 & 24 & Cukup & 22 & 22 & Cukup \\
\hline 6 & 20 & 29 & Baik & 21 & 22 & Cukup \\
\hline Mean & 18,67 & 26,00 & & 18,83 & 19,83 & \\
\hline $\mathrm{SD}$ & 3,93 & 4,69 & & 4,02 & 3,37 & \\
\hline \multicolumn{4}{|c|}{$\begin{array}{l}\text { Wilcoxon Signed Rank Test } \\
\qquad P=0,026\end{array}$} & \multicolumn{3}{|c|}{$\begin{array}{l}\text { Wilcoxon Signed Rank Test } \\
\mathrm{P}=0,063\end{array}$} \\
\hline \multicolumn{7}{|c|}{$\begin{array}{l}\text { Mann-Whitney U Test } \\
\mathrm{P}=0,030\end{array}$} \\
\hline
\end{tabular}

Tabel diatas menunjukkan pada kelompok perlakuan terdapat hubungan yang signifikan terhadap peningkatan motorik halus dengan memperhatikan uji statistik Wilcoxon Signed Rank Test yang menunjukkan nilai signifikan $\mathrm{p}=0,026$. Pada kelompok control menunjukkan hasil yang tidak signifikan dengan nilai $\mathrm{p}=$ 0,063. Hasil uji statistik Mann-Whitney U test menunjukkan perbedaan yang signifikan antara kelompok perlakuan dan kelompok kontrol dengan nilai $\mathrm{p}=0,030$.

\section{PEMBAHASAN}

\section{Analisis Perbedaan Keterampilan Motorik Halus pada Kelompok Perlakuan dan Kelompok Kontrol}

Berdasarkan analisa data yang didapatkan, kemampuan motorik halus anak retardasi mental pada kelompok perlakuan dan kontrol sebelum diberi intervensi terapi bermain menunjukkan sebagian besar berada pada kategori cukup $(83,33 \%)$. Setelah diberikan intervensi terapi bermain, data yang didapatkan pada kelompok perlakuan mengalami peningkatan kategori kurang menjadi cukup $(16,67 \%)$, dari kategori cukup menjadi baik $(66,67 \%)$, dan $6,67 \%$ tidak mengalami peningkatan kategori. Kelompok kontrol terjadi peningkatan kategori dari kurang menjadi cukup sebesar $16,67 \%$ dan responden yang tidak mengalami peningkatan kategori sebesar $83,33 \%$.

Anak retardari mental umumnya memiliki kecakapan motorik yang lebih rendah dibandingkan kelompok anak normal sebaya, baik secara kualitatif dan kuantitatif. Seringkali ditemui bahwa anak retardasi mental mengalami gangguan 
dalam motorik kasar, seperti ketika berjalan, melompat, berlari dan gerak lainnya serta motorik halus, seperti menangkap bola dan sebagainya. Kondisi ini dapat disebabkan adanya gangguan pada otak sebagai pusat motorik akibat dari gangguan pada pusat persepsi yang berhubungan dengan mental dan intelegensi (Sunardi \& Sunaryo, 2007).

Hal-hal yang dapat mempengaruhi perkembangan motorik halus adalah hereditas, lingkungan dan stimulasi. Hereditas merupakan faktor yang pertama sebagai warisan gen dari orang tua baik fisik maupun psikis yang didapat sejak masa konsepsi. Faktor lingkungan juga sangat berperan dalam tumbuh kembang anak yang bergantung pada keadaan lingkungan masing-masing anak serta keadaan jasmani dan rohani. Antara hereditas atau warisan gen dan lingkungan memiliki hubungan atau interaksi.

Berdasarkan data demografi orang tua responden pada kedua kelompok didapatkan bahwa sebagian besar pendidikan ayah dan ibu responden adalah SMA/sederajat. Pekerjaan ayah repsonden sebagian besar adalah pegawai swasta dan pekerjaan ibu sebagian besar adalah wiraswata atau pedagang kecil. Tingkat Pendidikan dan sosial ekonomi orang tua sangat berpengaruh dalam pemberian stimulsi perkembangan. Kurangnya pengetahuan orang tua dalam memberikan rangsangan selama masa tumbuh kembang anak dapat menjadi faktor terjadinya gangguan dalam perkembangannya.

Stimulasi diperlukan untuk meningkatkan perkembangan motorik halus, dalam hal ini peran serta orang tua sangat diperlukan untuk membimbing anak tersebut dalam melatih kemampuan motori halusnya. Stimulasi adalah hal penting selama masa tumbuh kembang anak. Anak yang banyak mendapat rangsangan yang terarah dan berkelajutan memiliki perkembangan yang lebih cepat dibandingkan anak yang kurang atau bahkan tidak mendapat stimulasi. Berbagai jenis stimulasi seperti stimulasi visual, verbal, auditif, taktil, dll dapat memaksimalkan perkembangan anak. Perhatian dan rasa sayang dari orang tua juga merupakan stimulasi yang penting pada awal perkembangan anak, misalnya mengajak bercakap-cakap, membelai, mencium, bermain, dll (Soetjiningsih, 2002).

Menurut Hurlock (2010) terdapat beberapa hal penting dalam mempelajari keterampilan motorik yaitu, kesiapan belajar, kesempatan belajar, kesempatan berpraktek, model yang baik, bimbingan dan motivasi. Cara umum mempelajari keterampilan motorik adalah 1) trial and error), tidak adanya bimbingan dan model 
untuk ditiru sehingga keterampilan motorik kurang beekembang; 2) meniru, belajar dengan meniru atau mengamati suatu model lebih cepat daripada belajar dengan trial and error; 3) pelatihan, belajar dengan bimbingan dan anak menirunya dengan tepat sangat pentig di tahap awal belajar.

Sejalan dengan penelitian yang dilakukan oleh Mahar (2018), menyatakan bahwa Terapi bermain paper toys dapat meningkatkan kekuatan dan kemampuan gerakan motorik kasar anak retardasi mental.

Terapi bermain adalah usaha penyembuhan untuk mencapai perkembangan hal-hal tersebut diatas secara optimal dengan bermain sebagai media. Terapi bermain bagi anak retardasi mental adalah usaha membantu anak retardasi mental agar dapat berkembang dalam aspek fisik, intelektual, emosi dan social secara optimal melalui bermain (Astati, 1995). Terapi bermain : parallel play adalah permainan bersifat aktif secara mandiri, tetapi masih dalam satu kelompok, dengan harapan kemampuan anak dalam menyelsaikan tugas mandiri dalam kelompok tersebut terlatih dengan baik (Hidayat, 2008). Kegiatan terapi bermain: parallel play menganyam kertas melatih responden untuk aktif secara mandiri menyelesaikan tugasnya. Prinsip anyaman yaitu, memanfaatkan jalur melintang dan membujur. Kedua jalur ini disusun tumpeng tindih bergantian hingga bersatu (Sulastianto, 2006). Dengan responden menggunakan teknik tersebut secara berulang-ulang, responden akan terbiasa dalam mengkoordinasikan mata dengan gerakan tangan untuk memanipulasi suatu obyek. Melalui proses diatas terjadi peningkatan kecakapan motorik halus yang mengakibatkan perkembangan motoric halus anak meningkat.

\section{KESIMPULAN DAN SARAN}

\section{Kesimpulan}

Terapi bermain: parallel play menganyam kertas dapat meningkatkan keterampilan motorik halus anak dengan retardasi mental karena permainan bersifat aktif secara mandiri dan berkesinambungan, terarah dan berurutan sehinga anak mampu meningkatkan kualitas aktifitas dalam kehidupan seharihari.

\section{Saran}

Pada penelitian selanjutnya diharapkan agar dilakukan penelitian tentang latihan motoric halus dan kasar yang melibatkan responden dari anak dengan retardasi mental sedang dan berat. Bagi para pendidik di sekolah luar biasa khusunya jurusan $\mathrm{C}$ seabiknya menerapkan terapi bermain parallel play menganyam kertas dengan rutin, berkelanjutan dan lebih 
bervariasi untuk meningkatkan

perkembangan motoric halus anak retardasi

mental.

\section{REFERENSI}

Astati, 1995. Terapi Okupasi, Bermain dan Musik untuk Anak Tuna Grahita. Bandung: Departemen Pendidikan dan Kebudayaan Nasional

Delphie, B. 2006. Pembelajaran Anak Tuna Grahita: Suatu Pengantar dalam Pendidikan Inklusi. Bandung: Refika Aditama

Elvira, S.,Hadisukanto. 2010. Buku Ajar Psikiatri. Jakarta: Fakultas KEdokteran Universitas Indonesia

Gunarsa, S. 2008. Psikologi Perkembangan Anak dan Remaja. Jakarta: Gunung Mulia

Hidayat, A.A. 2008. Pengantar Ilmu Keperawatan Anak I. Jakarta: Salemba Medika

Hurlock, E.,B. 2010. Perkembangan Anak Jilid I Ed.6. Jakarta: Erlangga

Islam, M. Z., Farjana, S., \& Shahnaz, R. (2013). Stress among parents of children with mental retardation. Bangladesh Journal of Medical Science, 12(1), 74-80. doi:http://dx.doi.org/10.3329/bjms.v $12 \mathrm{i} 1.13354$

Mahar, Ainin Fitriana. 2018. Terapi Bermain Paper Toys Meningkatkan Kemampuan Motorik Anak Retardasi Mental. Skripsi tidak dipublikasikan. Universitas Airlangga.

Mahmudah, S. 2002. Perubahan Perilaku Kebersihan Diri Pasca Pelatihan Motorik Halus: Studi Terhadap Anak Tuna Grahita Sedang di SLB/C "Dharma Wanita" Lebo Sidoarjo. Thesis tidak dipublikasikan. Universitas Airlangga

Musfiroh, T. 2008. Cerdas Melalui Bermain. Jakarta: Grasindo.

Raina, S., Razdan, S., \& Nanda, R. (2012). Prevalence of mental retardation among children in RS pura town of jammu and kashmir. Annals of Indian Academy of Neurology, 15(1), 23-26. doi:http://dx.doi.org/10.4103/09722327.93271

Sadock, Benjamin, Virginia. 2010. Kaplan and Sadock: Buku Ajar Psikiatri Klinis Ed. 2. Jakarta: EGC

Soetjiningsih. 2002. Tumbuh Kembang Anak. Jakarta: EGC

Somantri, T. 2006. Psikologi Anak Luar Biasa. Bandung: Refika Aditama

Sulastianto, Harry. 2006. Seni Budaya untuk Kelas XI Seklah Menengah Atas. Jakarta: Gravindo Media Pratama

Sunardi, Sunaryo. 2007. Intervensi Dini Anak Berkebutuhan Khusus. Jakarta: Departemen Pendidikan dan Kebudayaan Nasional

Wong, Donna L et al. 2009. Buku Ajar Keperawatan Pediatrik Vol. 1. Jakarta: EGC

Yusuf, S. 2005. Psikologi Perkembangan Anak dan Remaja. Bandung: Remaja Rosdakarya 